\title{
Divulgação Científica na Educação em Ciências: experiências do ensino de Biologia e Matemática no projeto "EntreProfessores", da UEFS
}

\section{Marco Antonio Leandro Barzano}

Universidade Estadual de Feira de Santana

marco.barzano@gmail.com

\section{Maria de Lourdes Haywanon de Araújo}

Universidade Estadual de Feira de Santana

marialore10@gmail.com

\section{Wilson Pereira de Jesus}

Universidade Estadual de Feira de Santana

jesusw@uol.com.br

\section{Resumo}

O artigo apresenta o relato de experiência do projeto EntreProfessores do Laboratório Multidisciplinar da UEFS, em especial, da área de ensino de Biologia e Educação Matemática. Procura-se mostrar os trabalhos desenvolvidos a partir de encontros de formação inicial e continuada de professores, quais sejam: palestras, oficinas e debates com variados temas relacionados à divulgação e cultura científica. No LAMULI são avaliados e reformulados materiais pedagógicos e tecnológicos existentes e produzidos novos recursos baseados nas discussões teóricas que ocorrem nos grupos de estudo/projetos de pesquisa, alimentados principalmente pelas experiências vividas nas escolas, campo das práticas e estágios. As atividades foram desenvolvidas tanto por estudantes de Licenciatura em Ciências Biológicas e Matemática, bolsistas do PIBID, quanto por professores e professoras da rede pública de ensino que lecionam as respectivas disciplinas em três escolas públicas na cidade de Feira de Santana BA. Procuramos analisar os conhecimentos e saberes produzidos e sua relação com a divulgação da ciência.

Palavras-Chave: Ensino de Biologia. Educação Matemática. Divulgação Científica. PIBID.

\section{Scientific Dissemination in Science Education: experiences of the teaching of Biology and Mathematics in the project "Between Teachers" of the UEFS}

\section{Abstract}

The article presents the experience report of the project EntreProfessores of the Multidisciplinary Laboratory of the UEFS (LAMULI), in particular, the area of teaching of Biology and Mathematics 
Education. It seeks to show the works developed from meetings of initial and continuing teacher training, namely: lectures, workshops and debates with various topics related to dissemination and scientific culture. At LAMULI, existing pedagogical and technological materials are evaluated and reformulated, and new resources are produced based on the theoretical discussions that take place in the study groups / research projects, fed mainly by the experiences in the schools, field of practices and stages. The activities were developed by students of Biological Sciences and Mathematics, scholarship holders of the PIBID, as well as by professors of the public school that teach the respective disciplines in three public schools in the city of Feira de Santana - BA. We seek to analyze the knowledge produced and its relation to the dissemination of science.

Keywords: Teaching of Biology. Mathematics Education. Scientific divulgation. PIBID.

\section{Introdução}

Nas últimas décadas a divulgação científica vem ganhando centralidade nos diferentes espaços educativos (formal; não-formal; informal) e, para citar alguns exemplos, temos revistas, jornais, blogs, museus, teatro, cinema, letras de música, cordéis, televisão, história em quadrinhos, charges, kits, entre outros, que são artefatos que conseguem difundir as ciências, alcançando públicos de diferentes faixas etárias e classes sociais.

Esses artefatos divulgam vários temas que, no século passado, demoravam para serem apreciados pelos diferentes públicos, principalmente, pelo fato de a difusão ser mais comum nos jornais e revistas impressos e na televisão. A partir do avanço dos meios de comunicação e tecnologia, conseguiu-se aumentar exponencialmente a disseminação do conhecimento científico, atingindo uma maior parte do público que, não necessariamente, é o escolar.

Outro aspecto que consideramos necessário destacar diz respeito ao fato de que, atualmente, os temas são difundidos em uma grande velocidade, pois além da televisão, os jornais e revistas não são apenas impressos, como há algumas décadas, mas são virtuais, somando com outros difusores como blog e redes sociais.

$\mathrm{O}$ artigo apresenta o relato de experiências de pesquisa e extensão que envolvem atividades de Educação em Ciências, particularmente, voltados para o Ensino de Biologia e Educação Matemática, desenvolvidos em uma das ações do Laboratório Multidisciplinar das Licenciaturas (LAMULI) ${ }^{1}$ da Universidade Estadual de Feira de Santana (UEFS).

O LAMULI é um Projeto de Extensão da UEFS e é um dos espaços integradores das ações de formação de professores que envolvem, particularmente, o contexto das disciplinas de Estágio

\footnotetext{
${ }^{1}$ Projeto Laboratório Multidisciplinar das Licenciaturas, financiado pela CAPES/Prodocência.
} 
Supervisionado (formação inicial) e PIBID (formação inicial e continuada). Trata-se de um ambiente de aprendizagem, onde atuam a maioria das áreas de ensino que contemplam os cursos de Licenciatura, tratando de temas específicos da formação de cada área de conhecimento. Considerando que os projetos de extensão e pesquisa possuem o mesmo grau de importância na nossa atuação acadêmica, procuramos equalizá-los, de maneira que ambos possam contribuir para a formação inicial e continuada de professores.

No LAMULI são avaliados e reformulados materiais pedagógicos e tecnológicos existentes e produzidos novos recursos baseados nas discussões teóricas que ocorrem nos grupos de estudo/projetos de pesquisa, alimentados principalmente pelas experiências vividas nas escolas, campo das práticas e estágios.

No presente artigo trataremos das atividades do EntreProfessores, ação comum de encontros de formação, quais sejam: palestras, oficinas e debates com variados temas no âmbito do Ensino de Ciências e Biologia e da Matemática, que se referem à formação de professores dessas áreas e que se vinculam diretamente a estudantes dos Cursos de Pedagogia, Licenciatura em Biologia, Licenciatura em Matemática e professores da Educação Básica da rede pública.

Para a estrutura do texto, procuramos apresentar um breve panorama acerca dos temas educação formal, não-formal e informal, e divulgação científica, principalmente no campo do ensino de biologia e educação matemática, que fazem parte da nossa formação e atuação como pesquisadores e formadores de professores dessas áreas do conhecimento. A opção por iniciarmos o artigo com essa apresentação conceitual se deve ao fato, principalmente, por nosso interesse em mostrar o referencial teórico-metodológico que é central nas atividades do LAMULI. Logo em seguida, apresentamos as atividades relacionadas ao ensino de Ciências e Biologia que foram desenvolvidas tanto por estudantes de Licenciatura em Ciências Biológicas, bolsistas do PIBID, quanto por professores e professoras da rede pública de ensino que lecionam as respectivas disciplinas. Destacamos as atividades de extensão desenvolvidas em três escolas públicas na cidade de Feira de Santana - BA e procuramos analisar os conhecimentos e saberes produzidos e sua relação com a divulgação da ciência. Na terceira parte do texto discorremos acerca das ações desenvolvidas na formação inicial de professores de Matemática e discentes do Curso de Licenciatura em Matemática, vinculados ao PIBID, tanto nos espaços do LAMULI, quanto nas escolas de educação básica, envolvendo nesse caso, a formação continuada de professores e a comunidade escolar. 
O papel da divulgação científica no ensino de biologia e matemática são reafirmados na relação teoria-prática que assumimos em nossos trabalhos junto ao LAMULI e que consideramos importantes para novos sentidos da relação universidade-escola que envolvem trabalhos colaborativos.

\section{Educação formal, não-formal e informal e a divulgação científica}

Procuramos apresentar a "tipologia" da Educação, quais sejam: formal; não-formal e informal. Estas denominações tem vigorado no campo da Educação e, de certa maneira, têm contribuído para uma melhor compreensão das diferentes particularidades que assumem.

A caracterização tipológica realizada por Afonso (1989, p. 86-87) nos mostra que

por educação formal, entende-se o tipo de educação organizada com uma determinada sequência e proporcionada pelas escolas enquanto que a designação educação informal abrange todas as possibilidades educativas do decurso da vida do indivíduo, constituindo um processo permanente e não organizado. Por último, a educação nãoformal, embora obedeça também a uma estrutura e organização (distintas, porém das escolares) e possa levar a uma certificação (mesmo que não seja essa a sua finalidade), diverge ainda da educação formal no que respeita a não fixação de tempos e locais e à flexibilidade na adaptação dos conteúdos de aprendizagem a cada grupo concreto.

Esta caracterização ainda tem sido reconhecida e muito utilizada por alguns, principalmente, a partir das publicações dos estudos pioneiros de Gohn (2001) e Simson (2001), de caráter sociológico e muitas vezes voltados para espaços educativos relacionados com os movimentos sociais e organização não-governamental (ONG). Segundo Garcia (2009, p. 42), "ao estudar a área da educação não-formal no Brasil é possível perceber que até há bem pouco tempo essa modalidade educacional quase não era considerada como um campo específico dentro do contexto educacional”.

Trilla (1996) define a educação não-formal como todas aquelas instituições, atividades e âmbitos educativos que, por não serem escolares, têm sido criadas especificamente para satisfazer determinados objetivos educativos que, em síntese, possuem uma educação com métodos e objetivos definidos, mas que não estão circunscritos à educação formal.

Em recente texto de Marandino (2014) há uma profícua discussão sobre o que a autora nomeia de "modalidades educativas". Tanto na literatura internacional quanto na nacional, há uma falta de consenso nas distinções de formal, não-formal e informal. Em especial, na América Latina, estas modalidades ficaram associadas a uma dimensão política. Esta mesma autora menciona que as práticas pedagógicas, ações de ensino e aprendizagem ocorrem "nas escolas, em visitas a museus, parques ecológicos, jardins botânicos e zoológicos, mas também por meio de programas de rádio, TV, vídeo, cinema, mídia impressa voltada à divulgação da ciência” (MARANDINO, 2014, p. 272). 
Ao buscarmos informações sobre a produção da divulgação científica em periódicos e dissertações e teses, optamos por realizarmos essa busca no banco de dissertações e teses da plataforma Sucupira, que foram defendidas no período de 2013 a 2016, cuja área de concentração é a de Ensino de Ciências e Matemática², e utilizamos a palavra-chave "divulgação científica". Nosso objetivo foi de ter uma ideia sobre o quantitativo e áreas da educação em ciências que desenvolvem pesquisas sobre divulgação científica. Ao todo, encontramos 173 registros de dissertações e teses, cujos temas mais enfocados se referem a museus de ciências, leitura de textos (jornais e revistas), clubes e feiras de ciências; e as áreas que se destacam são: ciências, biologia, química, física e matemática.

Na próxima seção, mostraremos algumas atividades que temos desenvolvido no LAMULI nos últimos seis anos, em projetos de pesquisa e/ou de extensão, relacionados com o binômio museuescola.

\section{EntreProfessores de Ciências e Biologia: objetos expositivos, imagens}

Aproximando-nos dos estudos do currículo para compreendermos melhor o que acontece com a escola e fora dela, buscamos nos estudos empreendidos por Paraíso (2010, p.11) compreender a relação currículo e culturas (particularmente a científica e escolar), quando nos mostra que

o currículo existe e está aqui, ali, por aí, em diferentes espaços, com diferentes modos de existir, fazendo coisas distintas a diferentes pessoas. O currículo diz muito e é dito por muitos também. Ele diz sobre o tipo de sujeito que se deve com ele formar, sobre os saberes que devem ser ensinados e aprendidos, sobre como conhecer o que foi aprendido, sobre o tipo de sociedade e os valores a serem construídos. [...] O currículo acontece na cultura, no cotidiano e também na mídia. [...] Trabalhamos, assim, com uma concepção de currículo que o entende como um artefato cultural que ensina, educa e produz sujeitos, que está em muitos espaços desdobrando-se em diferentes pedagogias.

Foi também com esse pensamento que procuramos, no desenvolvimento de nossas ações de pesquisa e extensão, nos inserir no interior da escola e entrar em contato com suas culturas. Desse modo, foi necessário investigar a cultura escolar e suas implicações para os currículos das disciplinas de Ciências, Biologia e Matemática, além da cultura científica que está imbricada com a escolar.

No diagnóstico realizado por bolsistas de iniciação do PIBID Biologia, foi encontrado nos laboratórios de Ciências das escolas uma grande quantidade de instrumentos antigos, além de modelos e maquetes, conforme as figura 1. Inspirados no trabalho de Zancul (2009), organizamos e

\footnotetext{
${ }^{2}$ Para o escopo do presente trabalho, procuramos focar na área de ensino de Ciências e Matemática por considerar que esta área contempla o ensino de biologia, química, física e matemática.
} 
inventariamos estes objetos, com o objetivo de analisar a importância para a cultura escolar e, também, para a divulgação histórica da ciência, pois consideramos que, desse modo, esta atividade pôde contribuir para a preservação da memória da escola, em suas culturas escolar e científica. Os objetos, constituintes de uma cultura científica, guardam a memória e história do museu e, certamente, eles “ensinam” e contribuem para a divulgação e história da ciência.

Figura 1 - Objetos científicos do laboratório da escola
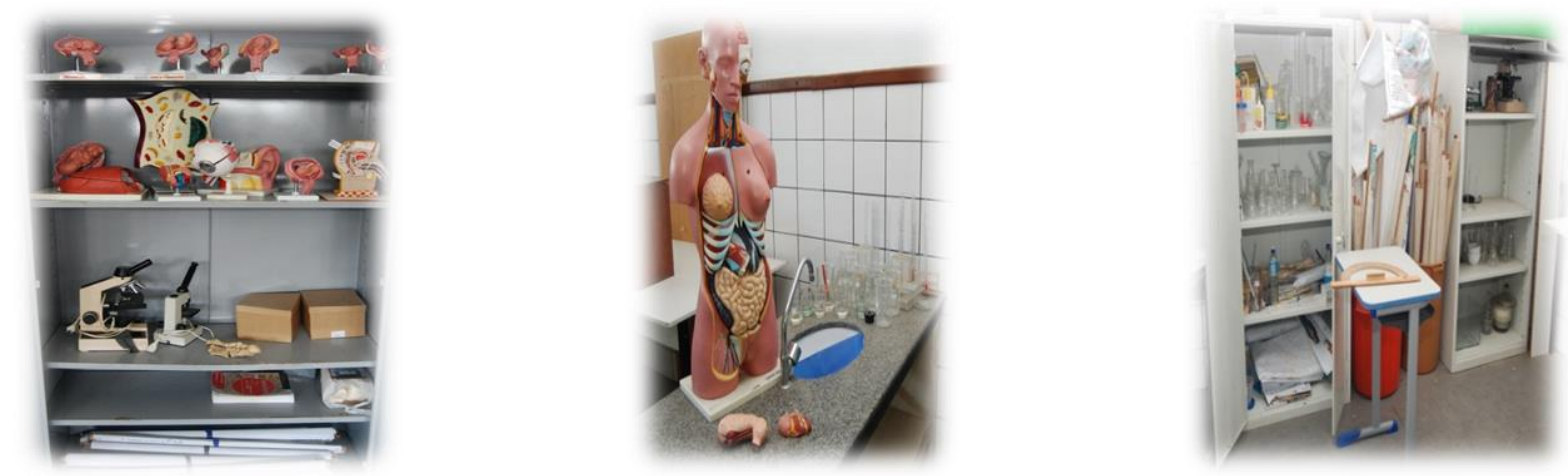

Fonte: Arquivo Marco Barzano

Segundo Zancul (2009, p. 7),

os aparelhos e instrumentos destinados ao ensino das disciplinas científicas, construídos e utilizados em diferentes épocas, localizados no laboratório de Física desta escola, constituem objetos de especial interesse de estudo para a compreensão da história do ensino de Ciências e de Física no Brasil. Tais materiais podem ser relacionados a programas, instruções metodológicas e a propostas pedagógicas formuladas em diferentes momentos e correspondem a diversos enfoques dados à experimentação ao longo do tempo.

Durante dois anos, procuramos desenvolver atividades com os estudantes do PIBID de Biologia, tratando do tema museu-escola, já que defendemos que na formação inicial os licenciandos devem ter a oportunidade de estabelecer um contato mais direto com os espaços de educação nãoformal e não somente com a escola, como acontece na maioria das vezes nos cursos de Licenciatura.

Os estudos sobre exposições e objetos têm mostrado o foco voltado para os sujeitos que produzem/criam/inventam tais artefatos, aqueles que estruturam e elaboram o discurso expositivo que é uma ferramenta analítica importante para o processo educativo e comunicativo, como apontam Marandino, Amorim e Barão (2005).

Segundo Marandino e colaboradores (2005), o discurso expositivo está entre os objetos e o público como fonte de educação. Este discurso, nas palavras dos autores, tem a natureza complexa e 
leva em consideração o objeto em si, os textos, imagens, maquetes e também o próprio espaço onde o objeto está sendo exposto. Dentro desta perspectiva, estes autores afirmam que nos museus de ciências os objetos representam especificamente os conhecimentos produzidos pelos respectivos campos da ciência, ou seja, a biologia, a física, a química ou as geociências. Estes objetos, portanto, foram confeccionados para contar a história e o desenvolvimento de um determinado conhecimento, para apresentá-lo ou para ilustrá-lo.

A discussão da parceria museu-escola é fundamental, pois contribui para a educação científica e, particularmente, na formação inicial e continuada de professores (MARANDINO, 2003), e isto foi constatado em nossas atividades de pesquisa e extensão realizadas no LAMULI.

Vários trabalhos atestam que dentre os públicos que visitam os museus de ciências, o escolar é o que mais comparece nestas instituições, conduzidos por seus professores, em pequenos ou grandes grupos, com a finalidade de rever os conteúdos abordados em aulas anteriores, na escola, a partir de outras perspectivas de ensino ou para iniciar a aprendizagem sobre novos conteúdos que, nas aulas seguintes, serão ministrados na escola.

A iniciativa de recriar o laboratório em cada uma das três escolas em que o PIBID-Biologia atuou, possibilitou que este espaço pudesse se tornar orgânico, com plenas condições de funcionamento. A ida ao museu, por professores e estudantes, serviu como inspiração para que, após a reestruturação dos laboratórios, estes pudessem contribuir para o conhecimento científico, bem como para que os objetos que compunham esse espaço pudessem ser expostos. Para tal exposição, os professores e estudantes realizaram uma Mostra nomeada "Biologia na Praça", que foi uma exposição dos materiais laboratoriais, que envolviam assuntos de botânica, zoologia, corpo humano, mecânica e eletricidade. Este acontecimento foi realizado na praça pública, no centro da cidade de Feira de Santana e foi de caráter interdisciplinar com licenciandos do curso de Física.

Consideramos que esta exposição conseguiu expressar uma real atividade de divulgação da ciência, pois a população em geral, nos diferentes níveis de escolarização, etnia, crenças, classe social, faixa etária, puderam ter contato direto com o conhecimento escolar/científico que a escola e a universidade possuem. Isso reitera a possibilidade de pensar sobre a importância da divulgação científica, em lugares como praças públicas, pois a população circulante é aquela que frequentou a escola um dia (ou não), e se depara com algo "novo", aquilo que pode estar presente na escola, mas talvez esteve ausente no período em que estas pessoas frequentaram este espaço.

Antes de a exposição fazer parte da Mostra na praça, foi possível acompanhar previamente o trabalho exposto na própria escola e observamos o interesse dos estudantes, tanto na apresentação 
daquilo que era exposto, como no fato de eles ficarem surpresos ao saberem que aqueles objetos, mesmo fazendo parte do acervo da escola, no laboratório, eram tão distantes da realidade que eles viviam. Isto possibilita afirmar que a escola dispõe de artefatos que compõem a cultura escolar científica, mas algumas vezes não possibilita práticas em que o estudante possa ter maior contato com esses materiais, pois ele geralmente não frequenta o laboratório.

Além da escola e da praça, a Mostra ocorreu no shopping center da cidade e constatamos que neste espaço, o público foi bem diferenciado e contrastou-se daquele da praça pública, principalmente, no que se refere à classe social e ao público, pois é um lugar que é frequentado majoritariamente pela classe média e há um grande quantitativo do público infantil, que é mesclado com o público familiar, como pode ser visto na figura 2 .

Figura 2 - Mostra Expositiva no Shopping Center
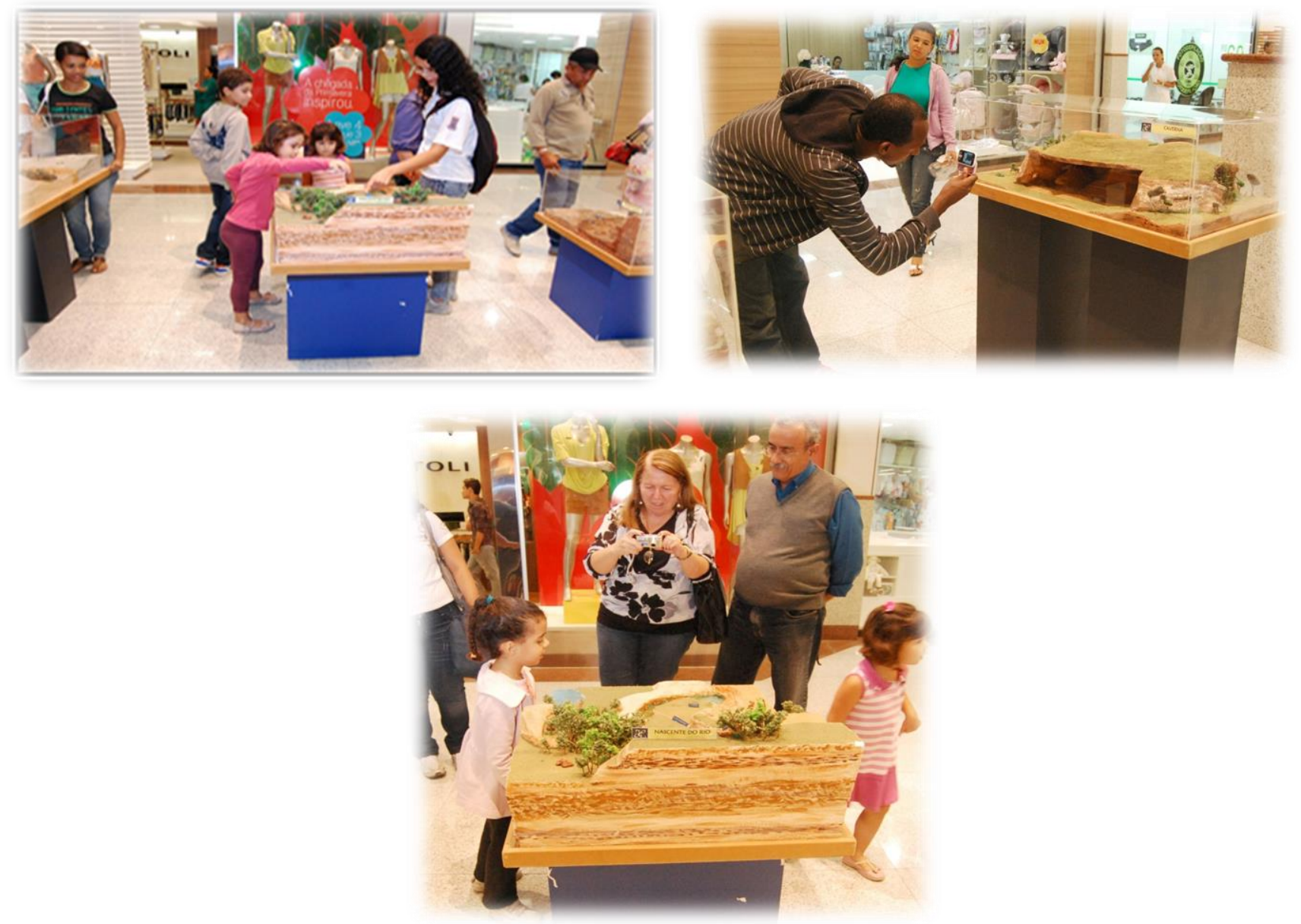

Fonte: Arquivo Marco Barzano 
Queremos defender neste artigo a intrínseca relação que tem ocorrido entre o binômio museuescola nas diferentes áreas do conhecimento, em especial, na Educação em Ciências e, para isto, é necessário rever o papel educativo do museu, principalmente o de Ciências, pois sabe-se que ele é um espaço educativo, de ensino-aprendizagem para qualquer público, mas o escolar, em particular, está na centralidade, e isto tem tido ressonância em suas práticas. O mesmo acontece com a escola - em particular as envolvidas em nossa pesquisa - que tem criado possibilidades de planejar e executar visita ao museu tanto para expandir aquilo que é ensinado, como para balizar o que ainda será ensinado, após a visita.

\section{EntreProfessores de Matemática}

O EntreProfessores de Matemática, no início de suas atividades, apresentou as potencialidades acerca de um tema que consideramos necessário de ser cultivado entre os professores da Educação Básica: as questões epistemológicas que devem permear a relação em meio a professores e alunos tendo em perspectiva a matemática.

Parece-nos conveniente que a reflexão acerca da atividade matemática deva ser precedida por uma, tão exaustiva quanto possível, reflexão acerca do conhecimento. Porque, pensamos, toda prática social, quando orientada ou esquadrinhada por uma teoria, tem maior chance de mostrar-se fértil e aquele que, verdadeiramente, teoriza acerca de sua ação, pode entrar em um processo cada vez mais refinado, de crítica e autocrítica, que se refletirá no aprimoramento do seu pensamento e, consequentemente, na qualidade da sua ação. Por isso, a ausência de reflexão histórica e filosófica - na esfera do ensino - "pode gerar práticas pedagógicas autoritárias no terreno da formação de professores de matemática" (JESUS, 2005 p.64).

As participações dos professores da área de matemática no EntreProfessores caracterizaram-se por abordagem de cunho epistemológico acerca da ciência, mesmo tendo como foco a Educação Matemática. Nesse sentido, uma primeira participação da Educação Matemática se deu sob o título Introdução à filosofia da matemática e a segunda participação enfocou o tema a Transposição Didática, segundo Ives Chevallard (1995). Consideramos que as discussões tratadas foram muito interessantes, com a participação de profissionais e estudantes da área de Ciências Biológicas e da área de Matemática.

A partir dessa experiência, avaliamos que talvez seja a possível vislumbrarmos um caminho consistente para a construção das possíveis soluções dos nossos históricos problemas vinculados ao ensino de matemática, se nos ativermos um pouco mais para uma das vertentes possíveis e quase nunca 
considerada nas nossas reflexões sobre educação matemática, a saber: encararmos as questões relativas ao conhecimento humano, ao conhecimento científico, ou seja, aquelas questões para as quais nunca teremos a resposta, mas que nos colocarão permanentemente em estado de atenção junto aos nossos colegas, aos nossos alunos, e ao lado dos pais desses alunos.

E quando nos detivermos ante essas questões, perceberemos que não há a resposta, porque o dinamismo do processo do conhecimento, ou seja, o movimento do mundo, da vida, de tudo, nos move no sentido de que o nosso conhecimento, aquele que nos cerca, é fugaz, está permanentemente mudando, embora aparente estabilidade das coisas no nosso modo de ver as coisas.

Vemos que é por causa da sala de aula, da nossa necessidade de transmissão da herança cultural do passado para as gerações futuras, que temos tantos problemas. Porque aprendemos, e não conseguimos compreender como os outros aprendem! Pensamos, e ficamos intrigados com a forma de pensar do outro, do qual não sabemos coisa alguma e nem nos atemos a saber. E o nosso foco é que o outro aprenda.

Curiosamente, o EntreProfessores é um espaço para aprofundar processos de reflexão acerca de peculiaridades da matemática e do ensino da matemática. As atividades de formação que envolvem os licenciandos do PIBID-Matemática têm como objetivo promover a autonomia para diversas atividades de ensino, pesquisa e extensão, bem como é importante que ao pôr em prática a transposição didática, o licenciando perceba a importância dos componentes teóricos do curso, como uma etapa de amadurecimento do pensamento matemático útil para sua autonomia em propor atividades diferenciadas que articulem teoria e prática.

Os resultados das diversas avaliações brasileiras e internacionais mostram que os alunos brasileiros, mesmo depois de terem frequentado a escola por muitos anos, são considerados mal alfabetizados matematicamente. Isso indica que eles, de modo geral, são capazes de ler os problemas apresentados e resolver apenas algoritmos postos claramente para a resolução, o que exige do sistema educacional brasileiro uma reação em busca do cumprimento do papel de preparar os estudantes para atuarem criticamente no mundo contemporâneo. Para tanto, é necessário que esses estudantes dominem conteúdos matemáticos necessários, mas também processos e procedimentos a serem desenvolvidos de modo a construir sua competência matemática.

As ações desenvolvidas no LAMULI partem da escolha de um conteúdo/tema de Matemática da Educação Básica que os bolsistas do PIBID indicam a partir das dificuldades que sentem à medida que desenvolvem atividades nas escolas. Mediante estudo teórico, com foco no esclarecimento de porquês e elucidação de fórmulas, são discutidas metodologias para as atividades na escola, 
priorizando a resolução de problemas, investigações, exercícios e projetos de intervenção que favoreçam o desenvolvimento de uma atitude investigativa tanto dos licenciandos quanto dos alunos da Educação Básica.

Concordamos com D’Ambrósio (s.d.) no trato da necessidade de reestruturar as propostas curriculares de Matemática da Educação Básica, ensinando os conceitos matemáticos fundamentais aliando-os à cultura local, pois entendemos, assim, que conceitos e procedimentos serão assegurados e poderão ser aplicados em qualquer contexto. Isso não implica na redução de conteúdos, mas em uma melhor articulação entre eles, e, ainda, num entendimento da concepção de Letramento Matemático no seu sentido mais amplo (ARAUJO, 2014).

Atuamos então na perspectiva de uma articulação de vários conteúdos matemáticos e com outras áreas de conhecimento, numa proposta de ensino pautada na resolução de problemas nos PCN/PCNM, aliada às diretrizes e matriz de referência das avaliações e dos projetos no qual a escola está inserida.

Essa articulação favorece o desenvolvimento de habilidades e competências que permitem ao aluno da Educação Básica resolver problemas envolvendo conceitos matemáticos, e também fortalece a formação do licenciando no trabalho articulado com diversos programas/projetos.

A ação desenvolvida, que citaremos como exemplo, iniciou com o estudo das operações aritméticas básicas e o uso do SOROBAN como estratégia didática. O objetivo inicial era aprender a manipular o SOROBAN para o ensino das operações básicas e, para nossa surpresa, a superficialidade no entendimento do Sistema de Numeração Decimal (SND) nos fez retroceder o estudo para entender a lógica de funcionamento de um sistema de numeração, manipulando inclusive em diversas bases, para que se tornasse evidente as vantagens do uso da base dez e a simplificação que a escolha da base gera nos procedimentos matemáticos.

Consideramos que uma das grandes dificuldades seja discutir com os bolsistas a diferença relacionada à aprendizagem desses conceitos por uma criança que não domina qualquer sistema e nós, professores, que dominamos as regras há muitos anos. Desconstruir o pensamento dos bolsistas que as regras, fórmulas e "macetes" precisam ter seus conceitos, serem esmiuçados e construídos pelos alunos, antes de ser utilizado, é um passo fundamental para que se procure entender teoricamente os conteúdos.

Avançando nessa fundamentação teórica aliada ao uso do SOROBAN, dúvidas conceituais vão sendo esclarecidas e aprofundadas, levando a outros conteúdos matemáticos e isso é interessante de se observar pois, a partir do SND, foi natural a passagem pelas operações aritméticas com números naturais e a evolução para a discussão dos números racionais e operações que os envolvem. 
A partir desse trabalho, a discussão principal que está sendo travada consiste na organização curricular que implica na ordem em que as operações aritméticas são abordadas, a necessidade e as consequências de se trabalhar as operações inversas - adição e subtração/multiplicação e divisão - em sequência, mas na maioria das vezes sem fazer qualquer relação ou mencionar esse fato. Os bolsistas discutem se não facilitaria a construção desse conhecimento ao se trabalhar as operações matemáticas conceitualmente próximas - adição e multiplicação/subtração e divisão - focando no conceito de adição/subtração sucessivas de mesmas parcelas. Esse debate nos encaminha para propor essa inversão na escola como experiência e verificar os resultados da aprendizagem.

Assim, nas ações propostas para formação inicial do Licenciando em Matemática, conseguimos promover uma mudança no olhar deste sobre o conhecimento matemático, sobre as metodologias de ensino, transpondo o debate para além dos muros da universidade, provocando na escola a discussão acerca de possibilidades de inovação e de novas perspectivas para o ensino de Matemática, em parceria constante.

Embora atendo-se a questões de fundo epistemológicas, o foco no processo de ensino da ciência não era o ensino nem a ciência, mas o aprendiz. Há no linguajar do nordeste uma palavra que dá conta desse ouvir atento, com todo o cuidado de um espírito desarmado, como faz o médico auscultando o paciente, a saber: assuntar, que quer dizer, prestar toda a atenção, olhando, ouvindo e escutando de forma acurada.

As atividades presentes no EntreProfessores da área de matemática apontaram para o viés da reflexão epistemológica em torno da ciência e do contexto cultural no qual brota a ciência, tendo em perspectiva que a ciência é um bem cultural, em que pese o jargão de que é fruto da ação tenaz de um indivíduo solitário.

\section{Considerações finais}

\footnotetext{
"Não cabe à divulgação científica apenas levar a informação, mas também atuar de modo a produzir as condições de formação crítica do cidadão em relação à ciência. Não só cabe à divulgação a aquisição de conhecimento e informação, mas a produção de uma reflexão relativa ao papel da ciência, sua função na sociedade, as tomadas de decisão correlatas, fomentos, aos apoios da ciência, seu próprio destino, suas prioridades e assim por diante". (VOGT, 2008)
}

Finalizamos o artigo com esse fragmento de uma entrevista com Carlos Vogt em que ele nos mostra o papel da divulgação científica, que não pode ser encarada como mera informação, mas atingir um amplo número de pessoas que tenham condições de obter o conhecimento científico necessário para o exercício da cidadania. 
As experiências do LAMULI que trouxemos para divulgar o que desenvolvemos em nossos projetos de extensão e pesquisa ocorreram nos últimos anos, que se caracterizaram a partir de palestras, minicursos e oficinas, envolvendo licenciandos, bolsistas do PIBID, dos cursos de Ciências Biológicas e Matemática; além de professores de três escolas públicas de Feira de Santana.

Inspirados em Carlos Vogt, vemos que nosso interesse na divulgação científica se dá, especificamente, ao público de estudantes dos cursos de Licenciatura, em especial, aos mencionados. Interessa-nos, portanto, abordar junto aos estudantes de Licenciatura, o tema divulgação científica, para que estes, em contato com a escola ou outros espaços educativos, possam levar à população diferentes maneiras de divulgar as ciências.

É imperativo que o planejamento não seja aleatório, descontextualizado, mas promova ao estudante uma divulgação científica capaz de permitir "o acesso às informações de ciência e tecnologia [como] fator importante para o exercício pleno da cidadania, fortalecendo a formação de uma cultura científica e possibilitando a construção de uma visão crítica acerca do processo do conhecimento científico pelos cidadãos" (SARMENTO et al, 2010 apud MARTINS; MARANDINO, 2013, p. 27).

Diante de nossas intenções ao coordenarmos o Laboratório Multidisciplinar das Licenciaturas, temos o interesse de que ele seja um espaço orgânico, uma extensão dos componentes curriculares em que estamos envolvidos, seja na formação inicial ou até mesmo na formação continuada de professores,

quando optamos em trabalhar com professores da educação básica que atuam no PIBID. Nosso propósito é de que esse laboratório seja um lugar de produção e difusão das ciências, mais do que meramente um lugar que informa as ciências.

\section{Referências}

AFONSO, A. J. Sociologia da Educação não-escolar: reactualizar um objecto ou construir uma nova problemática? In: Esteves, J. e Stoer, S.R. (orgs.). A Sociologia na Escola: professores, educação e desenvolvimento. Porto; Afrontamento, 1992.

ARAUJO, Maria de Lourdes H. S. O PISA no Brasil: uma análise da matriz de referência de matemática e o uso de seus resultados no contexto da educação brasileira. Tese de Doutorado. Universidade Federal da Bahia. Salvador, 2014.

CHEVALLARD, Yves. La transposición didáctica. Del saber sabio al saber enseñado. Buenos Aires: Aique Grupo Editor, 1995.

D'AMBROSIO, Ubiratan. Por que se ensina Matemática? Sd. Disponível em $<$ http://apoiolondrina.pbworks.com/f/Por\%20que\%20ensinar\%20Matematica.pdf> Acessado em Maio de 2014.

GARCIA, Valéria Aroeira. A educação não-formal como acontecimento. Tese de Doutorado. Universidade Estadual de Campinas, 2009. 
GOHN, M. da Glória. Educação não-formal: cultura política. 2a ed. São Paulo: Cortez, 2001.

JESUS, Wilson Pereira. Teoria do Conhecimento e Educação Matemática: reflexões. Cadernos de Física da UEFS, 03(02): 61-80, 2005.

MARANDINO, M. Espaços não formais no contexto formativo. In: BARZANO, M.A.L;

FERNANDES, J.A. B; FONSECA, L.C.S e SCHUWARTZ, M.(Orgs.) Ensino de Biologia:

experiências e contextos formativos. Goiânia: Índice Editora, 2014. pp. 169-180.

MARANDINO, M. Formação Inicial de Professores e os Museus de Ciências. In: SELLES, Sandra Escovedo; FERREIRA, Marcia Serra. (Orgs.). Formação Docente em Ciências: memórias e práticas. Niterói: EDUFF, 2003a p. 59-76.

MARANDINO, Martha; AMORIM, Antonio Carlos R. e BARÃO, Cristina de Carvalho. Percursos das Ciências em Exposições de Museus. In: MARANDINO, Martha et al. (orgs.) Ensino de Biologia: conhecimentos e valores em disputa. Niterói: Eduff, 2005.

PARAÍSO, Marlucy Alves. Currículo e Diferença. In: Marlucy Alves Paraiso.(Org.). Pesquisas sobre Currículos e Culturas: temas, embates, problemas e possibilidades. 1.ed.Curitiba: CRV, 2010, v. 1.

SIMSON, O. R. M. von et al. Introdução. In: SIMSON, O. R. M. von et al (orgs.). Educação nãoformal: cenários da criação. Campinas, SP: Editora da UNICAMP/ Centro de Memória, 2001.

TRILLA, Jaume Bernet. La educación fuera de la escuela: ámbitos no formales y educación social. Barcelona: Ariel, 1996.

VOGT, Carlos. Divulgação e Cultura Científica. Campinas: ComCiência: Revista Eletrônica de Divulgação Científica, 2008.

ZANCUL, Maria Cristina. A coleção de instrumentos antigos do laboratório de física da escola estadual Bento de Abreu, de Araraquara/SP. Ensaio: pesquisa em Educação em Ciências. Vol. 11 nº1, 2009.

MARTINS, L. C.; MARANDINO, Martha. (Org.). Formando Jovens Divulgadores da Ciência. 1. ed. São Paulo: Faculdade de Educação da USP, 2013. 97p.

Submetido em outubro de 2016

Aprovado em novembro de 2016 